\title{
Insulin sensitization via PPAR $\gamma$ and glucose uptake through activation of PI3K/p-Akt signaling pathway by resveratrol in type 2 diabetic rats
}

\author{
Faten Z. Mohammed ${ }^{1}$, Adel A. Gurigis ${ }^{2}$, Wael S. Abdel-Mageed², Aml Nassr ${ }^{1}$ \\ ${ }^{1}$ Chemistry Department, Faculty of science, Zagazig University, Zagazig, Egypt \\ ${ }^{2}$ Genetic Engineering and Biotechnology Institute, University of Sadat City, Egypt
}

\begin{tabular}{ll}
\hline A R T I L E I F O & A B S T R C T \\
\hline Type 2 diabetes & Background: Increasing evidence in both experimental \\
Resveratrol & and clinical studies suggests that there is a close link \\
Akt & between hyperglycemia, oxidative stress, and diabetic \\
PI3K $\gamma$ & complications. Resveratrol a polyphenolic compound \\
Irisin & found in various natural food products. Aim: The aim of \\
& the present study was to screen insulin sensitization via \\
& PPAR $\gamma$ and glucose uptake through activation of PI3K/p- \\
& Akt signaling pathway by resveratrol in type 2 diabetic \\
& rats Material and methods: Four groups male adult \\
& albino rats were used in this study: Negative control, \\
& Positive control, Therapeutic group and Standard group. \\
& Results: The treatment of resveratrol significantly \\
& reduced the elevated levels of blood glucose, Total \\
& cholesterol, Triglyceride, LDL-c, Urea and Creatinine in \\
positive control as compared with negative control. & Treatment of resveratrol also reverted back the decreased \\
levels of insulin, HDL-c, Irisin, enzymatic antioxidant \\
(catalase and superoxide dismutase) as well as decreased \\
level of the non-enzymatic antioxidant (reduced \\
glutathione) in tissue extracts from different organs of \\
diabetic rats to near normal values. Resveratrol \\
significantly increased expression of the PPAR $\gamma$ gene in \\
adipose tissue compared to positive control. It also \\
\hline
\end{tabular}


regulated insulin mediated glucose uptake in adipose tissue through activation of $\mathrm{PI} 3 \mathrm{~K} / \mathrm{p}-\mathrm{Akt}$ signaling pathway. PPAR $\gamma$ gene showed many different expressions for other side the PPAR $\gamma$ sequences from the adipose tissue confirm there is a mutation with the gene isolated from positive control against therapeutic group, meaning the Type 2 diabetes cause a mutation in the gene sequencing compared to negative control. Hence, we find the opposite with the PPAR $\gamma$ sequencing in therapeutic group. Conclusion: These results clearly suggest that the resveratrol has an antioxidant effects and could improve adipose tissue insulin sensitivity and maintain glucose homeostasis in adipose tissue.

두 2016 Publisher All rights reserved.

\section{INTRODUCTION}

Diabetes mellitus is a chronic metabolic disorder that constitutes a major public health problem throughout the world [1] and is characterized by chronic hyperglycemia due to abnormal insulin secretion or insulin receptor and post receptor events affecting metabolism of carbohydrate, protein and lipids ${ }^{[2]}$. Type 2 diabetes is the most common form of the disease and usually involves insulin resistance and $\beta$-cell dysfunction ${ }^{[3]}$. Insulin resistance which is the inability of cells to respond adequately to normal levels of insulin occurs primarily within the muscles, liver, and fat tissue [4]. Diabetes mellitus is associated with the production of reactive oxygen species (ROS) and consequently oxidative stress [5]. The increased oxidative stress due to free radical and accompanying decrease in antioxidants may be related to the complication of diabetes mellitus. Streptozotocin-diabetes provides a relevant example of endogenous chronic oxidative stress owing to hyperglycemia [6]. Hyperglycemia promotes the liberation of oxygen radicals which reduces the antioxidant in addition to damage pancreatic $\beta$-cells ${ }^{[7]}$. Irisin has been identified as a novel myokine that drives brown -fat- like conversion of white adipose tissue ${ }^{[8]}$. It also has been regarded as an anti-inflammatory factor, which is correlated to diabetes and severity of insulin resistance [9]. Herbal medicines important in the primary health care have been used for thousand years to fight diseases and improve body functions. Polyphenols present in these herbal remedies are considered as major nutrients responsible for improving general health and for providing cure for certain specific pathological conditions ${ }^{[10]}$. Resveratrol is a non- flavonoid polyphenol compound abundant in grapes, peanuts and other foods that are commonly consumed as part of human diet [11]. Humans have been exposed to dietary polyphenols for millions of years and have developed tolerance to this group of plant defense compounds ${ }^{[12]}$. Resveratrol has a variety of benefits on the health including antiinflammatory ${ }^{[13]}$, free radical scavenging ${ }^{[14]}$ anticarcinogenic ${ }^{[15]}$ as well as 
cardiovascular protective [16] and neuroprotective activities ${ }^{[17]}$. The aim of the present study was to investigate the antioxidant property of resveratrol against the hyperglycemia - induced oxidative stress in normal and diabetic rats including animal models of nicotinamide streptozotocin induced type 2 diabetes mellitus. Furthermore, this work was aimed to evaluate the insulin sensitization via PPAR $\gamma$ and glucose uptake through activation of $\mathrm{PI} 3 \mathrm{~K} / \mathrm{p}$-Akt signaling pathway by Resveratrol.

\section{MATERIALS AND METHODS:}

\section{Materials:}

Streptozotocin (STZ), nicotinamide (NIC) and Resveratrol were purchased from sigma chemicals Co. (St. Louis, Mo. USA) stored at $-20^{\circ} \mathrm{c}$ and protected from light. Metformin $\mathrm{HCl}$ was purchased from chemical of industries development (CID) company, Egypt) as tablets. All other chemicals used in this study were purchased from standard commercial suppliers and were of analytical grade. BIOZOL reagent was purchased from BIOER TECHNOLOGY. MMLV Reverse Transcriptase, dNTPs, Taq polymerase, primers for PCR were purchased from Bioline.

\section{Experimental Animals}

Adult male albino rats weighing 200-280 gm were housed at the experimental animal house of the faculty of science, Zagazig University. The animals were maintained in controlled environment of temperature, humidity and light. The rats had free access to tap water and a commercial pellet rat chaw ad libitum.

\section{Induction of Type 2 Diabetes in Rats}

Type 2 diabetes was induced in rats by a single intraperitoneal (i.P) injection of Streptozotocin (50 mg / kg body weight, STZ) in overnight fasting rats followed by the i.P administration of Nicotinamide (120 mg/kg b.wt, NIC) after 15 minutes.
STZ was dissolved in cold citrate buffer (100mM, pH 4.5) and always freshly prepared for immediate use within $5 \mathrm{~min}$., while NIC was dissolved in $0.9 \%$ (wt/v) sodium chloride ${ }^{[18]}$. The blood glucose levels in the animals were measured at 72 hours after the drug administration and those rats with fasting blood glucose levels greater than $250 \mathrm{mg} / \mathrm{dl}$ were considered to be diabetic and used for the further study [19]

\section{Experimental design:}

In this experiment, the rats were divided into 4 groups (10 rats in each group) as following:

Group I: Negative control (comprises normal rats).

Group II: Positive control (received (50 $\mathrm{mg} / \mathrm{kg}$ b.wt, STZ) followed by the i.p administration of Nicotinamide (120 $\mathrm{mg} / \mathrm{kg}$ b.wt, NIC) after 15 minutes.

Group III: Therapeutic group Diabetic rats administrated with Resveratrol $(5 \mathrm{mg} / \mathrm{kg} \mathrm{b.wt} / \mathrm{d})$ in aqueous solution orally for 30 days.

Group IV: Standard group Diabetic rats administrated orally with metformin (100 mg/kg b.wt/d) dissolved in distilled water for 30 days.

The dosage was adjusted every week according to any change in body weight to maintain similar dose per $\mathrm{kg}$ body weight of rat over the entire period of study for each group and administrated to rats daily.

\section{Samples collection:}

At the end of the experiment and after last treatment, rats were fasted overnight; the blood samples were collected from the retro-orbital venous plexus under light ether anesthesia. where, blood samples were collected in three types of tubes, first containing sodium fluoride for estimation 
of blood glucose, second containing ethylene diamine tetra acetic acid (EDTA) to get plasma by centrifugation at 4000 rpm for $20 \mathrm{~min}$ and third in empty tubes to get serum by centrifugation at $4000 \mathrm{rpm}$ for $20 \mathrm{~min}$. all these forms were used for various biochemical measurements.

A portion of Liver, heart, kidney and pancreas tissues were homogenized in icecold tris-Hcl buffer (100mM, pH 7.4) using Teflon homogenizer to prepare a10\% (w/v) tissue homogenate for determination of reduced glutathione(GSH). An aliquot of the whole tissue homogenate was centrifuged at $10000 \mathrm{rpm}$ for $15 \mathrm{~min}$ at $4^{\circ} \mathrm{C}$ and the cytosolic supernatant was used for determination of the superoxide dismutase activity (SOD) and CAT. A portion of liver In addition to adipose tissue and skeletal muscle from each group were suspended in RNA later solution and stored at $-70{ }^{\circ} \mathrm{C}$ until RNA extraction.

\section{Biochemical parameters:}

\section{Determination of glucose}

Plasma glucose was estimated by using a commercial kit derived from Elitech Clinical Systems, France ${ }^{[20]}$.

\section{Determination of serum insulin}

Serum insulin was estimated by using a commercial kit derived from SIEMENS Company, USA ${ }^{[21]}$.

\section{Determination of lipid profile}

Serum Cholesterol and triglycerides were estimated by using a commercial kit derived from Spin react Company, Spain [22] and from vitro Scient Company, Germany [23] respectively. Serum high density lipoprotein Cholesterol (HDL-c) was estimated by using a commercial kit derived from vitro Scient Company, Germany [24]. Low density lipoprotein Cholesterol (LDL-c) and very low density lipoprotein (VLDL) were estimated according to the equations ${ }^{[25]}$.

\section{Determination of Irisin}

Irisin concentration was determined by using a commercial kit derived from Glory Science Co., Ltd ${ }^{[26]}$.

\section{Determination of kidney function tests}

Serum samples were screened for kidney function tests including urea and creatinine by using a commercial kit derived from Diamond Diagnostic Company, Germany [27] and from Spin react Company, Spain ${ }^{[28]}$ respectively.

\section{Determination of catalase (CAT)}

Plasma and tissue CAT were estimated by using a commercial kit derived from Biodiagnostic Company, Egypt ${ }^{[29]}$.

\section{Determination of superoxide dismutase (SOD)}

Tissue SOD was estimated by using a commercial kit derived from Biodiagnostic Company, Egypt ${ }^{[30]}$.

\section{Determination of Glutathione reduced (GSH)}

Tissue GSH was estimated by using a commercial kit derived from Biodiagnostic Company, Egypt ${ }^{[31]}$.

\section{RNA Extraction and Reverse Transcriptase-Polymerase Chain Reaction (RT-PCR)}

RNA was extracted from liver, adipose tissue and skeletal muscle which are kept in RNA later by using BIOZOL reagent derived from BIOER TECHNOLOGY ${ }^{[32]}$. In RT-PCR, RNA was first reverse transcribed into DNA complement (cDNA) using reverse transcriptase enzyme. The following gene specific primers (forward and reverse) were used for the generation of cDNAs $^{[33]}$ :

PPAR $\gamma$ : The sequence of PPAR $\gamma$ primers and length of PCR products were as follows: $\quad$ Forward: TCAGGGCTGCCAGTTTCG-3' and reverse: 5'-GCTTTTGGCATACT CTGTGATCTC-3'. Product size: 1400 bp.

PI3K $\alpha$ : The sequence of PI3K primers and length of PCR products were as follows: Forward: 5'CAAAGCCGAGAACCTATTGC-3' and 
reverse: 5'-GGTGGCAGTCTTGT

TGATGA-3'. Product size: 1220 bp.

P-Akt: The sequence of p-Akt primers and length of PCR products were as follows: Forward:

5'-

CCGCTATTATGCCATGAAGAT- $3^{\prime}$ and reverse: 5'-TGTGGGCGACTT CATCCT3'. Product size: $220 \mathrm{bp}$.

$\boldsymbol{\beta}$-actin: The sequence of $\beta$-actin primers and length of PCR products were as follows: $\quad$ Forward: 5'TGTTGTCCCTGTATGCCTCT-3' and reverse: 5'-TAATGTCACGCAC GATTTCC-3'. Product size: 320 bp.

PCR products were run on $1.2 \%(\mathrm{w} / \mathrm{v})$ agarose gel, stained with ethidium bromide and photographed.

\section{DNA sequencing and analysis}

Three PPAR $\gamma$ (Adipose tissue) PCR fragments were sequenced using sequencing facilities (ABI 3130xl Genetic Analyzer and ABI 3730xl DNA Analyzer). Multiple sequence alignments were performed using Clustal W program provided on European Bioinformatics Institute (EBI) server (http://www.ebi.ac.uk/Tools/clustalw2/) and analyzed with BioEdit 7.0 software (Tom Hall, Ibis Therapeutics).

\section{Statistical analysis}

All statistical analyses were done by a statistical for social science package "SPSS" version 14.0 for Microsoft Windows, SPSS Inc. ${ }^{[34]}$. Numerical data were expressed as mean \pm SD. The levels of markers were analyzed by ANOVA. The correlations between biochemical data in different studied groups were evaluated by Box blots.

\section{RESULTS:}

\section{Plasma glucose and insulin}

Our results showed the levels of plasma glucose and insulin of normal and experimental rats. There was a significant $(p<0.0001)$ elevation in plasma glucose, while the levels of insulin significantly $(p<0.0001)$ decreased in the positive control (diabetic rats) as compared with negative control (normal rats). A significant $(\mathrm{p}<0.0001)$ decrease in plasma glucose and increase in insulin levels were observed in therapeutic group as well as in standard group. Moreover, normal rats did not exhibit any significant alterations in plasma glucose and insulin levels during the experimental period as shown in Table (1) and fig. (1-2).

\section{Lipid profile}

Our results showed the levels of total cholesterol, triglycerides, high density lipoprotein-C (HDL-C), low density lipoprotein-C (LDL-C) and very low density lipoprotein-C (VLDL-C) in the serum of rats of different groups. Positive control had significantly $(\mathrm{p}<0.0001)$ elevated levels of serum total cholesterol, triglycerides, LDL-C and VLDL-C and significantly $(\mathrm{p}<0.0001)$ decreased level of high density lipoprotein-C (HDL-C). Treatment with resveratrol or metformin prevented the above changes in diabetic rats and improved towards normal levels as shown in Fig. (3-7).

\section{Irisin}

Our results indicated that a significant decrease of plasma irisin in positive control (diabetic group) when compared with negative control (normal rats) but, the diabetic rats treated with resveratrol (therapeutic group) or metformin (standard group) showed an extreme significant ( $\mathrm{p}<$ 0.0001 for both groups) elevation in irisin nearly to the normal value as shown in Fig. (8).

\section{Kidney function tests}

Our results showed a significant increase in urea and creatinine levels of positive control compared to negative control but in the diabetic rats administered with resveratrol ( therapeutic group), urea level still remained significantly higher ( $\mathrm{p}=$ 0.007) in comparison to negative control but creatinine level slightly decreased 
when compared with positive control in addition to the diabetic rats treated with metformin (standard group) showed a significant decrease in urea level $(\mathrm{p}<$ 0.0001 ) and a significant decrease in creatinine level $(\mathrm{p}<0.0001)$ when compared with positive control as shown in Fig. (9-10).

\section{Effect of Resveratrol on enzymatic and non-enzymatic antioxidants}

Our results revealed that enzymatic antioxidants (Catalase and Superoxide dismutase) as well as non-enzymatic antioxidant (Glutathione reduced) were found to be lower in positive control compared to that negative control. These antioxidant levels significantly $(\mathrm{p}<$ 0.0001) increased to a level closer to the normal values in therapeutic group and standard group as shown in fig. (11-23).

\section{Gene Transcriptional Changes}

In liver tissue: The PCR product of (PPAR $\gamma$, PI3K $\alpha$, p-Akt and $\beta$-actin) were analyzed, PPAR $\gamma$ PCR product showed the expected size of $1450 \mathrm{bp}$, but its absent with the +ve: positive control (diabetic group), St: standard (Metformin) group, PI3K $\alpha$ and $\beta$-actin PCR products showed the expected size of 1210 and $320 \mathrm{bp}$ respectively with different treatments and p-Akt PCR product showed the expected size of $220 \mathrm{bp}$, but its absent with the The: Therapeutic (Resveratrol) group as shown in Fig. (24).

In skeletal muscle: PPAR $\gamma$ PCR product showed the expected size of $1450 \mathrm{bp}$, but its absent with the The: Therapeutic (Resveratrol) group, PI3K $\alpha$ PCR product showed the expected size of $1210 \mathrm{bp}$, but its absent with the St: standard (Metformin) group, $\beta$-actin PCR products showed the expected size of 320 bp with different treatments and p-Akt PCR product showed the expected size of 220 bp, but its changed in molecular weight with the The: Therapeutic (Resveratrol) group as shown in Fig. (25).
In adipose tissue: PPAR $\gamma$ PCR product showed the expected size of $1450 \mathrm{bp}$, but its absent with the St: standard (Metformin) group, PI3K $\alpha$ PCR product showed the expected size of $1210 \mathrm{bp}$, with -ve: Negative control, The: Therapeutic (Resveratrol) group, but its absent with $\mathrm{St}$ : standard (Metformin) group, +ve: positive control (diabetic group), $\beta$-actin PCR products showed the expected size of 320 bp with different treatments and p-Akt PCR product showed the expected size of 220 bp, but its absent with the The: Therapeutic (Resveratrol) group as shown in Fig.(26).

\section{DNA sequencing and analysis}

Three PPAR $\gamma$ (Adipose tissue) PCR fragments were sequenced using sequencing facilities (ABI 3130xl Genetic Analyzer and ABI 3730xl DNA Analyzer). The sequences of the PPAR $\gamma$-ve: Negative control, +ve: positive control (diabetic group), and The: Therapeutic (Resveratrol group) were aligned and carefully analyzed. The analysis revealed differences between -ve and The in 17 amino acids and -ve and +ve in 30 amino acids, and between +ve and The in 13 amino acids (Fig. 27).

\section{DISCUSSION:}

Diabetes mellitus is considered a metabolic disease characterized by many various groups of disorders that disturb carbohydrate, protein and fat metabolism [35]. The loss of glucose homeostasis and shortage or lack of insulin secretion is owing to diabetes syndrome [36]. Hyperglycemia promotes the liberation of oxygen radicals which reduces the antioxidant potential in the body and has been shown to damage of pancreatic $\beta$ cells ${ }^{[37]}$. GLUT-4 transporter is specifically expressed in two insulinsensitive tissues i.e. adipose tissue and skeletal muscle and is essential for glucose uptake. Insulin resistance is due to impaired glucose transport by defects in insulin-mediated GLUT-4 translocation. Since adipose tissue is an insulin-sensitive 
organ, resistance to insulin, resulting impaired vesicle GLUT-4 transfer affected glucose uptake by adipocytes ${ }^{[38]}$. Our results indicated that hyperglycemia was confirmed in the experimental animals $(489.99 \pm 38.58 \mathrm{mg} / \mathrm{dl})$ in addition to the significant decrease in insulin level as compared to negative control. Treatment with Resveratrol or Metformin showed remarkably reduced in blood glucose level and ameliorated the elevation in insulin as compared with diabetic rats. Resveratrol improved insulin resistance in diabetic rats compared with positive control and there is evidence that resveratrol enhances insulin secretion and insulin tissue sensitivity in streptozotocin - nicotinamide induced diabetic rats. Resveratrol binding to the sulfonylurea receptor in pancreatic $\beta$ cell membrane is the mechanism of its action on insulin secretion. So that stimulation and activation of these receptors is associated with ATP-sensitive $\mathrm{K}^{+}$channels blockage and therefore plasma membrane depolarization and the subsequent insulin release from pancreatic $\beta$ cells ${ }^{[39]}$. In addition to that resveratrol has a non - insulin dependent effect triggering some of the similar intracellular insulin signaling such as increased expression and translocation of the GLUT4 transporter ${ }^{[40]}$.T2DM conditions are frequently associated with dyslipidemia which leads to the development of insulin resistance ${ }^{[41]}$ and is a significant risk factor for the development of cardiovascular disease ${ }^{[42]}$. Elevated circulating free fatty acid level is due to severe accumulation of epididymal adipose deposition in diabetic subjects ${ }^{[43]}$. Our results revealed that administration of resveratrol as well as metformin to T2DM animals decreased significantly the levels of serum total cholesterol, triglyceride, low density lipoprotein (LDL) cholesterol and very low density lipoprotein (VLDL) cholesterol as well increased high density lipoprotein (HDL) cholesterol this may be due to the phenolic hydroxyls contained in resveratrol structure through oxidation which leads to suppression of cholesterol, oxidation of unsaturated fatty acids, suppression of platelet aggregation, prevention accumulation of cholesterol and fat in the blood, improvement of peripheral blood circulation and thus prevention exerting hyperlipidemia ${ }^{[44]}$. Irisin secretion after Peroxisome proliferator-activated receptor gamma coactivator-1-alpha (PGC-1 $\alpha$ ) activation in response to the exercise could enhance insulin sensitivity and increase energy expenditure in animal experiments [45] furthermore, irisin stimulates browning of white adipose tissue through induced phosphorylation of p38 mitogen -activated protein kinase (p38 MAPK) and extracellular signal -regulated protein kinase (ERK) signaling pathway to prevent obesity and T2DM [46]. Our results revealed that a significant decrease of plasma irisin in positive control (diabetic group) when compared with negative control (normal rats) but, the diabetic rats treated with resveratrol (therapeutic group) or metformin (standard group) showed an extreme significant $(\mathrm{p}<0.0001$ for both groups) elevation in irisin nearly to the normal value. Through our result of the diabetic rats administered with resveratrol (therapeutic group), urea level still remained significantly higher in comparison to negative control but creatinine level slightly decreased when compared with positive control in addition to the diabetic rats treated with metformin (standard group) showed a significant decrease in urea level and a significant decrease in creatinine level when compared with positive control. The elevation of serum urea and creatinine levels in diabetic rats may indicate diminished ability of the kidneys to filter these waste products from the blood and excrete them in the urine ${ }^{[47]}$. The production of highly reactive oxygen species that are toxic to the cell, particularly the cell membrane in which these radicals interact with the lipid bilayer and produce lipid peroxides is induced by 
oxidative stress ${ }^{[48]}$. In type 2 diabetes, excessive ROS could promote the inhibition of insulin synthesis [49]. The activity of the antioxidant enzymes, such as SOD and CAT are decreased in the tissues of diabetic rats. This may result in a number of deleterious effects due to the accumulation of ROS ${ }^{[50]}$. One possible mechanism for this reduction in SOD and CAT activities may be due to the inactivation caused by the excess of free radicals and/or by non-enzymatic glycation due to the persistent hyperglycemia, which has been extensively reported to occur in diabetes [51]. Catalase is involved in the elimination of $\mathrm{H}_{2} \mathrm{O}_{2}{ }^{[52]}$ whereas superoxide dismutase acts to dismutate superoxide radicals to $\mathrm{H}_{2} \mathrm{O}_{2}$ which is then acted upon by GPx ${ }^{[53]}$. Our results indicated that the administration of resveratrol or metformin to the diabetic rats significantly $(\mathrm{p}<$ 0.0001 ) increase the antioxidant enzyme activities, plasma and different tissues extracts of catalase and superoxide dismutase when compared with diabetic rats (positive control). The capacity of resveratrol to scavenge ROS is due to its ability to upregulate mRNA expression for antioxidant enzymes [54] and may be attributed to a hydrogen- electron donation from its hydroxyl groups ${ }^{[55]}$. Thus the observed increasing in the antioxidant enzyme activities in different organ extracts in diabetic rats administered with resveratrol (therapeutic group) compared to un treated one (positive control) reflects the antioxidant potential of resveratrol. Non enzymatic antioxidants play a vital role in protecting cells from oxidative damages [56]. A decreased GSH content may predispose the cells to lower defense against condition of oxidative stress during several degenerative disease conditions including aging and diabetes ${ }^{[57]}$. From the current results it can be revealed that diabetic rats treated with resveratrol (therapeutic group) or with metformin (standard group) resulted in a significant increase in GSH levels of different tissue extracts of liver, kidney, heart and pancreas in therapeutic group and in standard group when compared with positive control. Resveratrol exerts great protection against $\mathrm{H}_{2} \mathrm{O}_{2}$ induced oxidative injury through increased GSH levels ${ }^{[58]}$. Our results revealed a good outcome of using the RSV on the biochemical assay and molecular level as well; against the results from the standard (Metformin) group compared for three different genes Akt, PI3k and PPAR $\gamma$, the consequence reveled there are many different on the gene expression in three tissues. The PPAR $\gamma$ gene showed many different expressions for other side the PPAR $\gamma$ sequences from the adipose tissue confirm there is a mutation with the gene isolated from the positive control against the therapeutic group, which meaning the T2DM causing a mutation in the gene sequencing compared with the negative control. Hence, we find the opposite with the PPAR $\gamma$ sequencing in therapeutic group. PPAR $\gamma$ is the molecular target to treat T2DM which is downregulated during tissue insulin resistance [59]. Scientific reports reveal that physiological activation of this receptor has been mediated by polyunsaturated fatty acids and their metabolites [60]. Our study revealed that resveratrol induced PPAR $\gamma$ expression in the adipose tissue of diabetic rats administered with resveratrol (therapeutic group). Although PPAR $\gamma$ was not upregulated in skeletal muscle. These findings suggested resveratrol normalized lipid metabolism. The PPAR family is involved in many aspects of lipid and glucose regulation such as fatty acid oxidation and adipogenesis [61]. In addition, the PPAR $\gamma$ gene encoding a transcription factor from a nuclear receptor family, which binds to specific DNA sequences (PPAR $\gamma$ responsive elements) in the promoter of other genes and influences their expression, is another gene found to be connected with the insulin resistant monogenic T2DM ${ }^{[62]}$. Based on its mechanism, PPAR $\gamma$ is also essential for 
insulin action and glucose homeostasis. Rare mutations in this gene result in the syndrome of severe insulin resistance and subsequent T2DM that is accompanied by partial lipodystrophy (absence of fat in the limbs and gluteal region), lipid abnormalities (high triglycerides, low HDL cholesterol), hypertension and hepatic steatosis ${ }^{[63]}$. Activation of glucose transporter is a crucial event in insulin signaling cascade that leads to effective glucose disposal into peripheral tissues ${ }^{[64]}$. Impaired glucose disposal in peripheral tissues is linked with abnormal insulin signaling through reduction in the $\mathrm{PI} 3 \mathrm{~K} / \mathrm{p}$ Akt expressions ${ }^{[65]}$. The blood glucoselowering effect of resveratrol in diabetic rats has been documented and found to be associated with a resveratrol-induced activation of Akt and endothelial NO synthase ${ }^{[66,67]}$. The phosphorylation of Akt is known to be an essential step of insulin signalling ${ }^{[68]}$. The skeletal muscles are a major site of glucose disposal ${ }^{[69]}$. Glucose transport, which depends on insulin-stimulated translocation of glucose carriers to the cell membrane, is the ratelimiting step in the carbohydrate metabolism of skeletal muscle ${ }^{[70]}$. Insulinstimulated glucose utilization is attributed primarily to the increase of glucose uptake in skeletal muscle ${ }^{[71]}$. Insulin-dependent diabetes such as in STZ-diabetic rats is a kind of abnormal metabolic state characterized by a deficiency in insulin secretion. Resveratrol can increase the utilization of glucose in the peripheral tissue via the insulin-independent mechanism ${ }^{[72]}$. Resveratrol was found to increase glucose uptake associated with the increase of Akt phosphorylation mediated via PI3K in the skeletal muscle. Furthermore, the expression of GLUT4 was upregulated in STZ-diabetic rats after repeated treatment with resveratrol ${ }^{[73]}$.

\section{CONCLUSION:}

Resveratrol as a strong antioxidant against hyperglycemia- induced oxidative stress in rat model of type 2 diabetes which in turn may be accountable for its antidiabetogenic property. Resveratrol lowered plasma glucose through insulindependent and-independent mechanisms. Resveratrol increased insulin secretion in rats with sufficient insulin secretion function; furthermore, resveratrol could also produce a hypoglycemic effect in insulin-deficient STZ-diabetic rats via PI3K-Akt-signaling pathway to enhance glucose uptake into skeletal muscle. PPAR $\gamma$ sequences from adipose tissue confirm there is a mutation with the gene isolated from positive control against therapeutic group, meaning the T2DM cause a mutation in the gene sequencing compared with negative control.

\section{REFERENCES:}

[1] Aloulou A., Hamden K., Elloumi D., Ali M.B., Hargafi K., Jaouadi B., et al.( 2012): Hypoglycemic and antilipidemic properties of kombucha tea in alloxaninduced diabetic rats. BMC Complement Altern Med; 12:63.

[2] American diabetes association (2008): Diagnosis and classification of diabetes mellitus. Diabetic care; 31(1): 55-60.

[3] Lupi R. and Del Prato S. (2008): Betacell apoptosis in type 2 diabetes: Quantitative and functional consequences. Diabetes Metab; 34 Suppl 2:S56-64.

[4] Williams LW. (2007): Diabetes Mellitus a Guide to Patient Care. Philadelphia: Lippincott Williams \& Wilkins; 15.

[5] Almeida D.A.T., Braga C.P., Novelli E.L.B., Fernandes A.A.H. (2012): Evaluation of lipid profile and oxidative stress in $\mathrm{n}$ STZ- induced rats treated with antioxidant vitamin. Braz. Arch. Biol. Technol; 55(4): 527-536.

[6] Punitha I.S.R., Rajendra K., Shirwaikar A., Shiwaikar A. (2005): Alcoholic stem extract of cascinium fenestratum regulates carbohydrate metabolism and improves antioxidant status in streptozotocin nicotinamide induced diabetic rats. Evid 
Based Complement Alternate Med.; 2(3): 375-381.

[7] Satheesh M.A. and L. Pari (2004): Antioxidant effect of Boerhavia diffusa L. in tissues of alloxan induced diabetic rats. Indian J Exp Biol.; 42(10): 989-992.

[8] Moreno-Navarrete J.M., Ortega F., Serrano M., Guerra E., Pardo G., Tinahones F. (2013): Irisin is expressed and produced by human muscle and adipose tissue in association with obesity and insulin resistance. J. Clin. Endocrinol. Metab; 98(4): E769-78.

[9] Liu J.J., Wong M.D., Toy W.C., Tan C.S., Liu S., Ng X.W. (2013): Lower circulating irisin is associated with type 2 diabetes mellitus. J. Diabetes Complications; 27(4): 365-9.

[10] Pandey K.B. and Rizvi S.I. (2010): Protective Effect of Resveratrol on Markers of oxidative Stress in Human Erythrocytes Subjected to In Vitro oxidative Insult. Phytother Res.; 24: S11S14.

[11] Vastano B.C. , Chen, Y. , Zhu, N. , Ho, C.T. , Zhou, Z. , Rosen, R.T. (2000): Isolation and identification of stilbenes in two varieties of Polygonum cuspidatum, J. Agric. Food Chem., 48: 253-256.

[12] Halls C. and Yu O. (2008): Potential for metabolic engineering of resveratrol biosynthesis, Trends Biotechnol.; 26: 7781.

[13] Wang L., O. Ma, X. Chen, M. Sha, Z. Ma (2008): Effect of resveratrol on calcium regulation in rats with severe acute pancreatitis. Eur. J. Pharmacol.; 580: 271-276.

[14] Jia Z., J. Zhu, B.R. Misra, et al., (2008): EPR studies on the super oxidescavenging capacity of the nutraceutical resveratrol. Mol. Cell. Biochem; 313: 187194.

[15] Bhardwaj A., Sethi G., Vadhan-Raj S., (2007): Resveratrol inhibits proliferation, induces apoptosis and overcomes chemoresistance through down regulation of STAT3 and nuclear factorKappa B- regulated anti-apoptotic and cell survival gene products in human myeloma cells. Blood; 109: 2293-2302.

[16] Das S., C.G. Fraga, D.K. Das, (2006): Cardioprotective effect of resveratrol via HO-1 expression involves p38 map kinase and P1-kinase signaling, but does not involve NF Kappa B. Free rad; 40: 10661075.

[17] Ates O., Cayli S., Altinoz E. (2007): Neuroprotection by resveratrol against traumatic brain injury in rats. Mol. Cell. Biochem; 2294: 137-144.

[18] Masiello P., Broca C., Gross R., Roye M., Manteghetti M., Hillaire-Buys D., Novelli M., Ribes G., (1998): Experimental NIDDM: Development of a new model in adult rats administered streptozotocin and nicotinamide. Diabetes; 47: 224-229.

[19] Kim M.J. and Lim Y., (2013): Protective effect of short-term genistein supplementation on the early stage in diabetes-induced renal damage. Mediators. Inflamm; 510212.

[20] Pruden E.L., Mc Pherson R.A., Fuhrman S.A., (1995): Clinical guide to laboratory tests- Ed. Tietz N.W. / Saunders W.B. Company. 3th ed. section 1: general clinical tests; 268-273.

[21] Bates H.M., (1983): Insulin and pheochromocytoma. Lab. Management. 21: 11 .

[22] Young D.S., (2001): Effects of disease on Clinical Lab. Tests, $4^{\text {th }}$ ed., AACC 2001.

[23] Stein E.A., (1987): Lipids, lipoproteins, and Apo lipoproteins. In: Tietz NW, ed. Fundamentals of Clinical Chemistry. 3rd ed. Philadelphia: WB Saunders. 448 - 481.

[24] Gotto A.M., (1988): Hospital practice, 23:Suppl.1-4.

[25] Nordestgaard B.G. and Benn M., (2009): Fasting and Nonfasting LDL Cholesterol: To Measure or Calculate? Clinical Chemistry; 55(5): 845-847.

[26] Young-Pearse T.L., Bai J., Chang R., Zheng J.B., LoTurco J.J., Selkoe D.J .J., (2007): A critical function for beta 
amyloid precursor protein in neuronal migration revealed by in utero RNA interference. Neurosci. Dec 26; 27(52):14459-69.

[27] Kaplan A., (1984): Urea, Kaplan A. et al. Clin Chem the C.V. Mosby Co. St Louis. Toronto. Princeton $1257-1260$ and 437 and 418.

[28] Young D.S., (1995): Effects of drugs on clinical lab. Tests. $4^{\text {th }}$ ed AACC press, 1995.

[29] Aebi H., (1984): Methods Enzymol; 105: 121-126.

[30] Nishikimi M., Roa N.A., Yogi K., (1972): Biochem. Bioph. Res. Common.; 46: 849-854.

[31] Beutler E., Duron O., Kelly MB., (1963): J. Lab clin. Med.; 61: 882.

[32] Chomczynski P. and Mackey K., (1995): Short technical report. Modification of the TRIZOL reagent procedure for isolation of RNA from Polysaccharide-and proteoglycan-rich sources. Bio techniques; 19(6): 942-5.

[33] Gandhi G. R., A. Stalin, K. Balakrishna, S. Ignacimuthu, M. G. Paulraj, R. Vishal. (2013): Insulin sensitization via partial agonism of PPAR $\gamma$ and glucose uptake through translocation and activation of GLUT4 in PI3K/p-Akt signaling pathway by embelin in type 2 diabetic rats. Biochimica et Biophysica Acta; 1830: 2243-2255.

[34] Levesque R., (2007): SPSS Programming and Data Management: A Guide for SPSS and SAS Users, Fourth Edition, SPSS Inc., Chicago I11.

[35] Rawi S.M., Mourad I.M., Sayed D.A., (2011): Biochemical changes in experimental diabetes before and after treatment with mangifera indica and psidium guava extracts. Int. J. pharm Biomed Sci.; 2(2): 29-41.

[36] Prasad S.K., Kulshreshtha A., Taj N.Q., (2009): Antidiabetic activity of some herbal plants in STZ- induced diabetic albino rats. Pak J. Nutr.; 8: 551-557.

[37] Satheesh M.A. and L. Pari (2004): Antioxidant effect of Boerhavia diffusa L. in tissues of alloxan induced diabetic rats. Indian J. Exp. Biol.; 42(10): 989-992.

[38] Farimani A.R., M. Saidijam, M.T. Goodarzi, R.Y. Azari, S. Asadi, S. Zarei, N. Shabab, (2015): Effect of Resveratrol Supplementation on the SNARE Proteins Expression in Adipose Tissue of Stroptozotocin-Nicotinamide Induced Type 2 Diabetic Rats. Iran J Med Sci; 40(3): 248-255.

[39] Hambrock A., de Oliveira Franz C.B., Hiller S., Grenz A., Ackermann S., Schulze D.U., Drews G., Osswald H. (2007): Resveratrol binds to the sulfonylurea receptor (SUR) and induces apoptosis in a SUR subtype-specific manner. J Biol Chem.; 282:3347-56. doi: 10.1074/jbc. M608216200. PubMed PMID: 17138562.

[40] Penumathsa S.V., M. Thirunavukkarasu, L. Zhan, G. Maulik, V.P. Menon, D. Bagchi, N. Maulik (2008): Resveratrol enhances GLUT-4 translocation to the caveolar lipid raft fractions through AMPK/AKT/eNOS signaling pathway in diabetic myocardium. J Cell Mol Med.; 12(6a): 2350-2361.

[41] Veerapur V.P., K.R. Prabhakar, B.S. Thippeswamy, P. Bansal, K.K. Srinivasan, M.K. Unnikrishnan, (2012): Antidiabetic effect of Ficus racemosa Linn. stem bark in high-fat diet and low-dose streptozotocin-induced type 2 diabetic rats: a mechanistic study, Food Chem. 132 : 186-193.

[42] Rao P.V., Madhavi K., Naidu M.D., (2011): Hypolypidemic properties of Rhinacanthus nasutus in Streptozotocin Induced Diabetic Rats. J. Pharm. Toxicol.; 6: 589-595.

[43] Yamabe N., H.Y. Kim, K.S. Kang, Q. Zhao, K. Matsumoto, T. Yokozawa, (2010): Effect of Chinese prescription Kangen-karyu on lipid metabolism in type 2 diabetic db/db mice, J. Ethnopharmacol.; 129: 299-305.

[44] Xie H., H. Han, Z. Chen, J. He, (2014): A Study on the Effect of Resveratrol on Lipid Metabolism in 
Hyperlipidemic Mice. Afr $J$ Tradit Complement Altern Med.; 11(1):209-212. [45] Swick A.G., Orena S., O'Connor A., (2013): Irisin levels correlate with energy expenditure in a subgroup of humans with energy expenditure greater than predicted by fat free mass. Metabolism;62:10701073.

[46] Zhang Y., Li R., Meng Y., Li S., Donelan W., Zhao Y., Qi L., Zhang M., Wang X., Cui T., Yang L.J., Tang D., (2014a): Irisin stimulates browning of white adipocytes through mitogenactivated protein kinase p38 MAP kinase and ERK MAP kinase signaling. Diabetes, 63:514-525.

[47] Ugwu M.N., Umar I.A., Utu-Baku A.B., Dasofunjo K., Ukpanukpong R.U.,Yakubu O.E., Okafor A.I. (2013): Antioxidant status and organ function in streptozotocin-induced diabetic rats treated with aqueous, methanolic and petroleum ether extracts of ocimum basilicum leaf. Journal of Applied Pharmaceutical Science; 3 (4): S75-S79.

[48] Kalaiarasi P. and Pugalendi K.V., (2011): Protective effect of 18 $\beta$ glycyrrhetinic acid on lipid peroxidation and antioxidant enzymes in experimental diabetes. Journal of Pharmacy Research; 4(1): 107-111. ISSN: 0974-6943.

[49] Robertson R.P. and Harmon J.S., (2007): Pancreatic islet beta-cell and oxidative stress: the importance of glutathione peroxidase. FEBS Lett; 581: 3743-8.

[50] Stevens M.J. (2005): Redox-based mechanisms in diabetes, Antioxid. Redox Signal; 7: 1483-1485.

[51] Rains J.L. and Jain S.K., (2011): Oxidative stress, insulin signaling, and diabetes. Free Radic. Biol. Med.; 50: 567575.

[52] Liedias F., Rangel B., Hansberg W., (1998): Oxidation of catalase by siglet oxygen. J. Biol. Chem., 273: 1063010637.

[53] McCord J. M., Keele B.B., Fridorich I., (1976): An enzyme based theory of obligate anaerobiosis? The Physiological functions of superoxide dismutase. Proc. Nath. Acad. Sci. USA., 68: 1024.

[54] Leonard S.S., Xia C., Jiang B.H., $\underline{\text { Stinefelt B., Klandorf H., Harris G.K., Shi }}$ $\underline{X}$. (2003): Resveratrol scavenges reactive oxygen species and effects radical-induced cellular response. Biochem Biophys Res. Commun; 309(4): 1017-26.

[55] Lüpez-Velez M., Martínez-Martínez F., Del Valle-Ribes C., (2003): The study of phenolic compounds as natural antioxidants in wine, Crit. Rev. Food Sci. Nutr. 43: 233-244.

[56] Davi G., A. Falco, C. Patrono, (2005): Lipid peroxidation in diabetes mellitus. Antioxid. Redox Signal; 7: 256268.

[57] Rizvi S.I. and P.K. Maurya, (2007): Markers of oxidative stress in erythrocytes during aging in humans. Ann. N.Y. Acad. Sci.; 1100: 373-382.

[58] Yen G.G., P.D. Duh, C.W. Lin, (2003): Effect of resveratrol and 4hexylresoainol on hydrogen peroxideinduced oxidative DNA damage in human lymphocytes. Free Radic. Res.; 37: 509514.

[59] Plutzky J., (2003): PPARs as therapeutic targets: reverse cardiology? Science; 302: 406-407.

[60] Reilly S.M. and C. Lee, (2008): PPAR $\gamma$ as a therapeutic target in metabolic disease, FEBS Lett. 58: 26-31.

[61] Wilson C., (2011): Diabetes: T2DMPPARgamma ligands without the adverse effects? Nat Rev Endocrinol; 7(11): 630.

[62] Scacchi R., A. Pinto, O. Rickards, A. Pacella, G.F. De Stefano, C. Cannella, R.M. Corb, (2007): An analysis of peroxisome proliferator-activated receptor gamma (PPAR-gamma 2) Pro12Ala polymorphism distribution and prevalence of type 2 diabetes mellitus (T2DM) in world populations in relation to dietary habits. Nutr Metab Cardiovasc Dis; 17(9): 632- 641.

[63] Mellor D.D., Sathyapalan T., Kilpatrick E.S., Beckett S., Atkin S.L. 
(2010): High-cocoa polyphenol-rich chocolate improves HDL cholesterol in Type 2 diabetes patients. Diabet Med; 27(11): 1318-21.

[64] Choi S.S., B.Y. Cha, K. Lida, Y.S. Lee, T. Yonezawa, T. Teruya, K. Nagai, J.T. Woo, Artepillin C. (2011): as a PPAR $\gamma$ ligand, enhances adipocyte differentiation and glucose uptake in 3T3L1 cells, Biochem. Pharmacol; 81: 925933.

[65] Muthusamy V.S., C. Saravanababu, M. Ramanathan, R.B. Raja, S. Sudhagar, S. Anand, B.S. Lakshmi, (2010): Inhibition of protein tyrosine phosphatase $1 \mathrm{~B}$ and regulation of insulin signaling markers by caffeoyl derivatives of chicory (Cichoriumintybus) salad leaves, Br. J. Nutr. 104: 813-823.

[66] Thirunavukkarasu M, Penumathsa SV, Koneru S, et al. (2007) Resveratrol alleviates cardiac dysfunction in streptozotocin induced diabetes: role of nitric oxide, thioredoxin, and heme oxygenase. Free Radic Biol Med; 43: 720729.

[67] Rivera L., Moro’n R., Zarzuelo A., et al. (2009): Long-term resveratrol administration reduces metabolic disturbances and lowers blood pressure in obese Zucker rats. Biochem Pharmacol 77, 1053-1063.

[68] Avogaro A., de Kreutzenberg S.V., Fadini G.P. (2008): Oxidative stress and vascular disease in diabetes: is the dichotomization of insulin signaling still valid? Free Radic Biol Med; 44: 12091215.

[69] Ziel F.H., Venkatesan N., Davidson M.B., (1988): Glucose transport is rate limiting for skeletal muscle glucose metabolism in normal and STZ-induced diabetic rats. Diabetes 37 (7), 885-890.

[70] De-Fronzo, R.A., (1988): The triumvirate: $\beta$-cell, muscle, liver. A Collusion responsible for NIDDM.

Diabetes 37 (6), 667-687.

[71] Hirshman M.F., Goodyear L.J., Wardzala L.J., Horton E.D., Horton E.S. (1990): Identification of an intracellular pool of glucose transporters from basal and insulin stimulated rat skeletal muscle. Journal of Biological Chemistry 265 (2), 987-991.

[72] Su H.C., Hung L.M., Chen J.K. (2006): Resveratrol, a red wine antioxidant, possesses an insulin-like effect in streptozotocin-induced diabetic rats. American Journal of Physiology: Endocrinology and Metabolism 290 (6) E00487-2005.R2.

[73] Tzong-Cherng Chi, Win-Pin Chen, Tsung-Li Chi, Tzong-Fu Kuo, ShoeiSheng Lee, Juei-Tang Cheng, Ming-Jai Su. (2007): Phosphatidylinositol-3-kinase is involved in the antihyperglycemic effect induced by resveratrol in streptozotocininduced diabetic rats Life Sciences; 80: 1713-1720.

Table 1: The effect of resveratrol on glucose and insulin levels

\begin{tabular}{|l|l|c|c|c|c|}
\hline Groups & $\begin{array}{c}\text { Glucose(mg/dl) } \\
\text { Mean } \pm \text { SD }\end{array}$ & \% change & $\begin{array}{c}\text { Insulin( } \boldsymbol{\mu u} / \mathbf{m l}) \\
\text { Mean } \pm \text { SD }\end{array}$ & \% change & P value \\
\hline Negative control & $88.76 \pm 8.14$ & - & $13.26 \pm 0.55$ & - & - \\
\hline Positive control & $489.99 \pm 38.58$ & 452.0 & $2.50 \pm 0.67$ & -81.1 & $<0.0001$ \\
\hline $\begin{array}{l}\text { Therapeutic } \\
\text { group }\end{array}$ & $89.98 \pm 5.14$ & 1.4 & $16.24 \pm 0.77$ & 22.5 & $<0.0001$ \\
\hline Standard group & $87.32 \pm 2.82$ & -1.6 & $8.19 \pm 0.24$ & -38.2 & $<0.0001$ \\
\hline
\end{tabular}




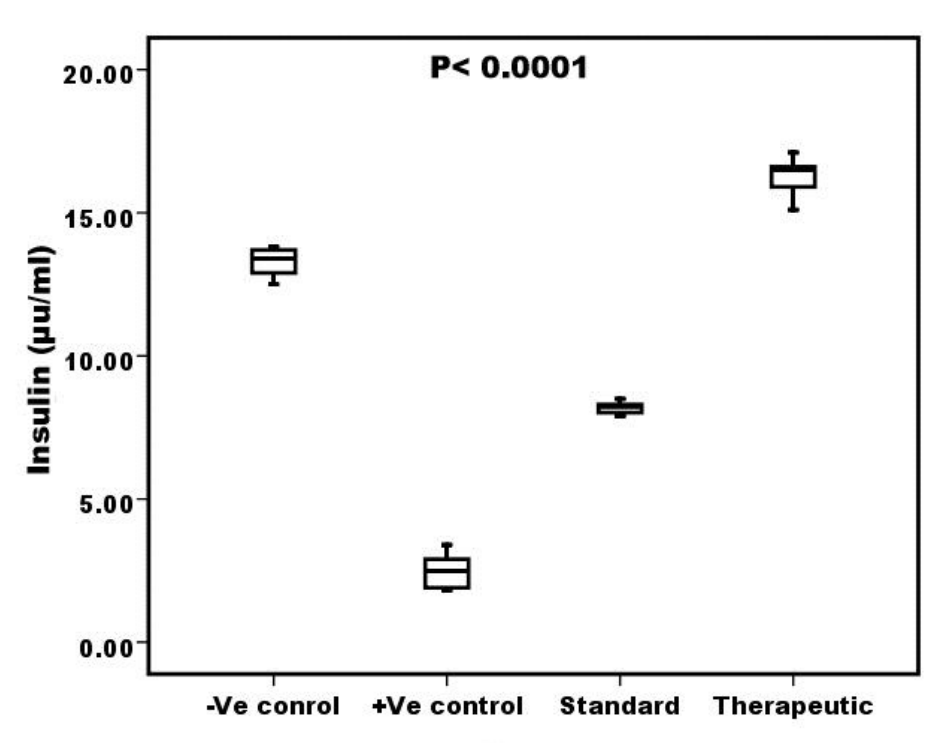

Fig. (1): Box plots of insulin for comparison between Different studied groups

-ve $=$ Negative control and +ve $=$ Positive control.

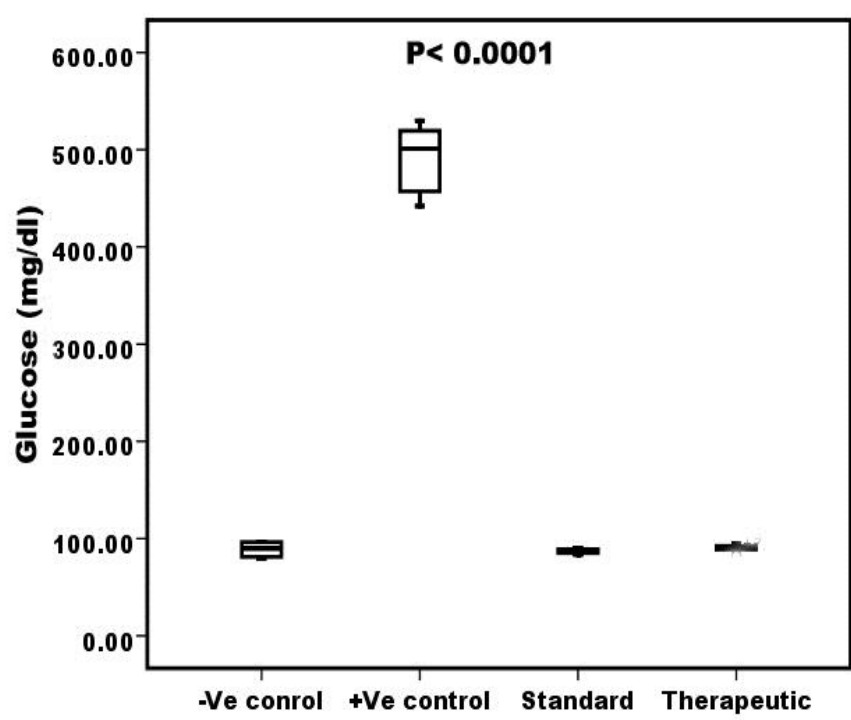

Fig. (2): Box plots of glucose for comparison between Different studied groups

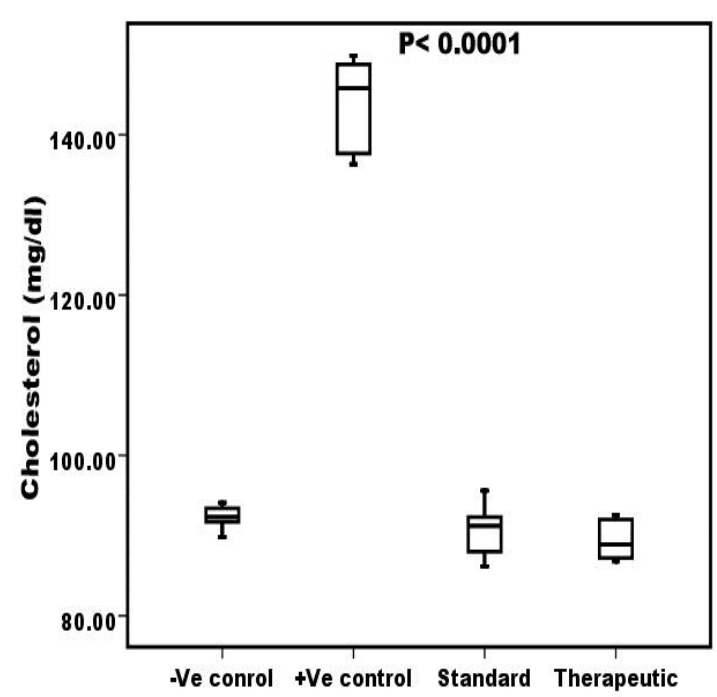

Fig. (3): Effect of Resveratrol on Cholesterol studied in all studied groups

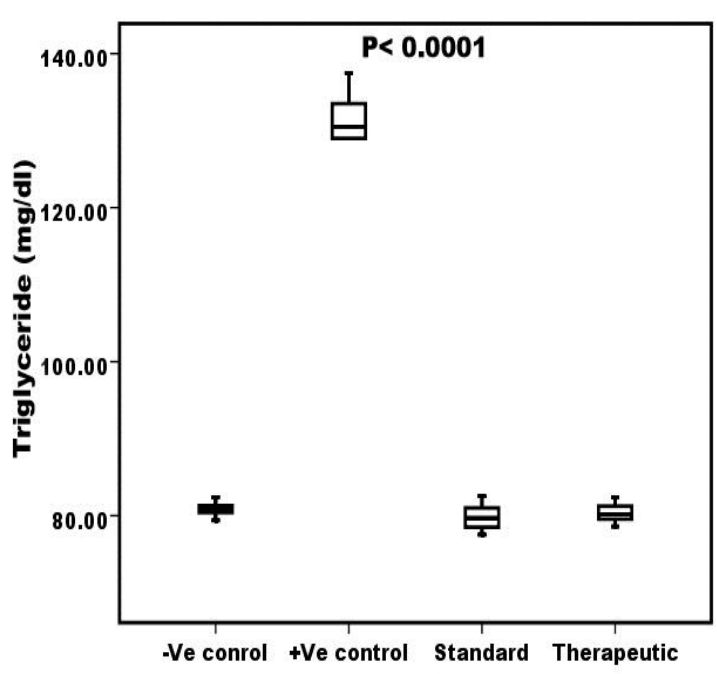

Fig. (4): Effect of Resveratrol on Triglyceride in all groups 


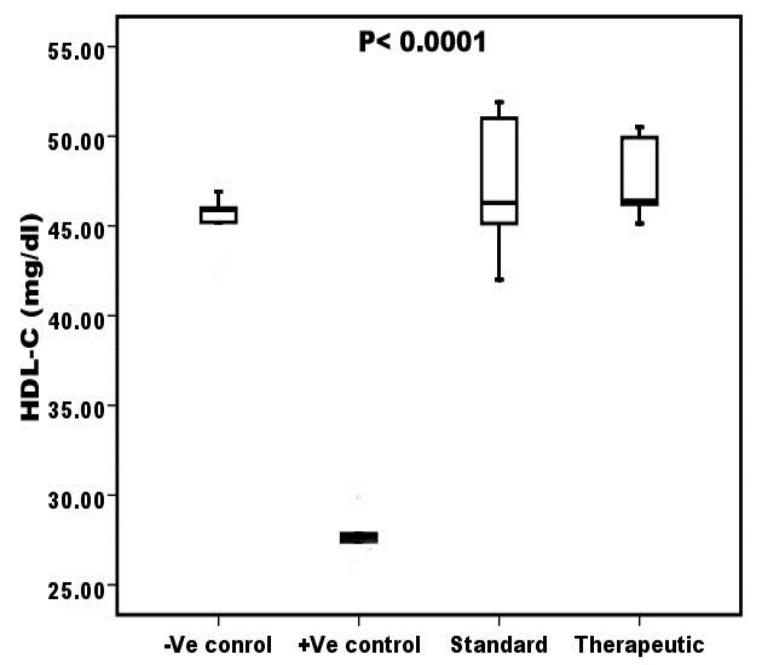

Fig. (5): Box plots of HDL-C for comparison between Different studied groups

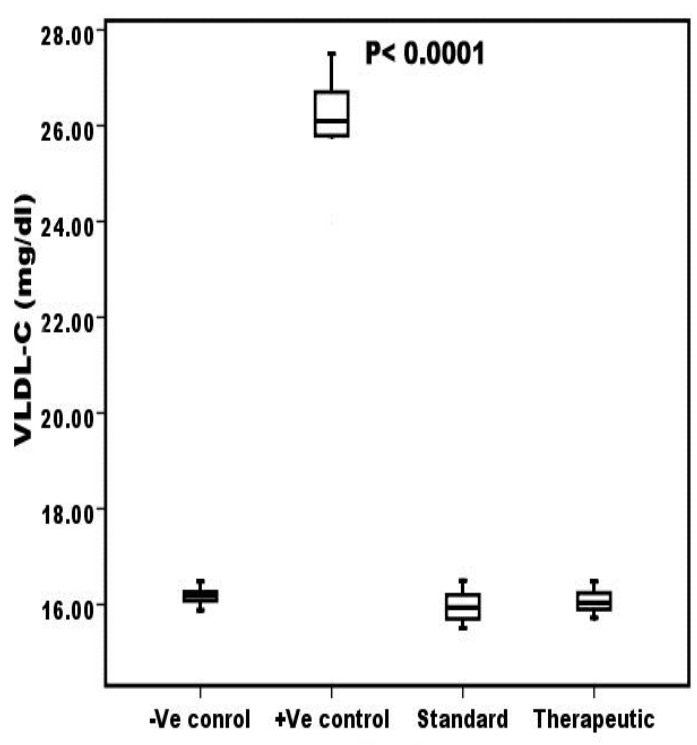

Fig. (7): Box plots for VLDL-C between Different studied groups

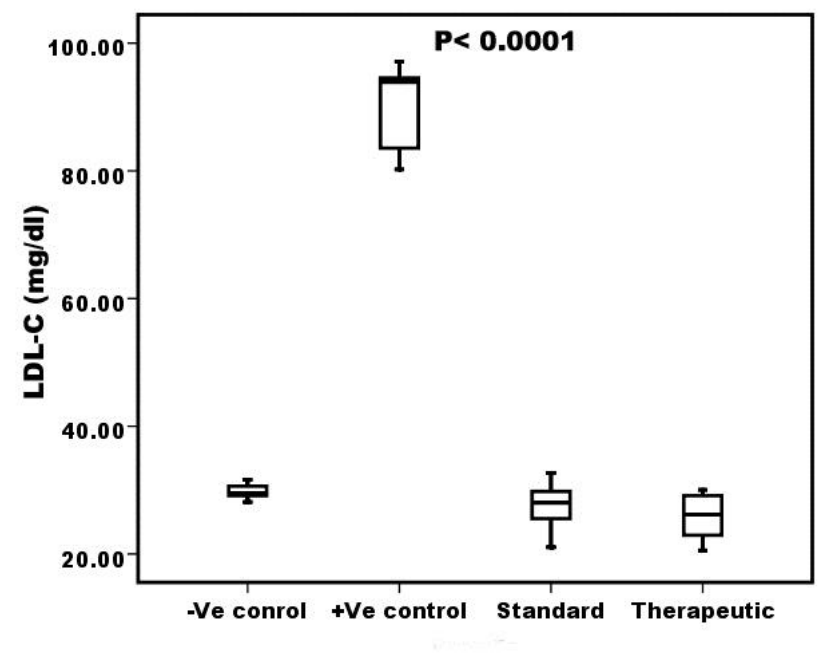

Fig. (6): Box plots of LDL-C for comparison between Different studied groups

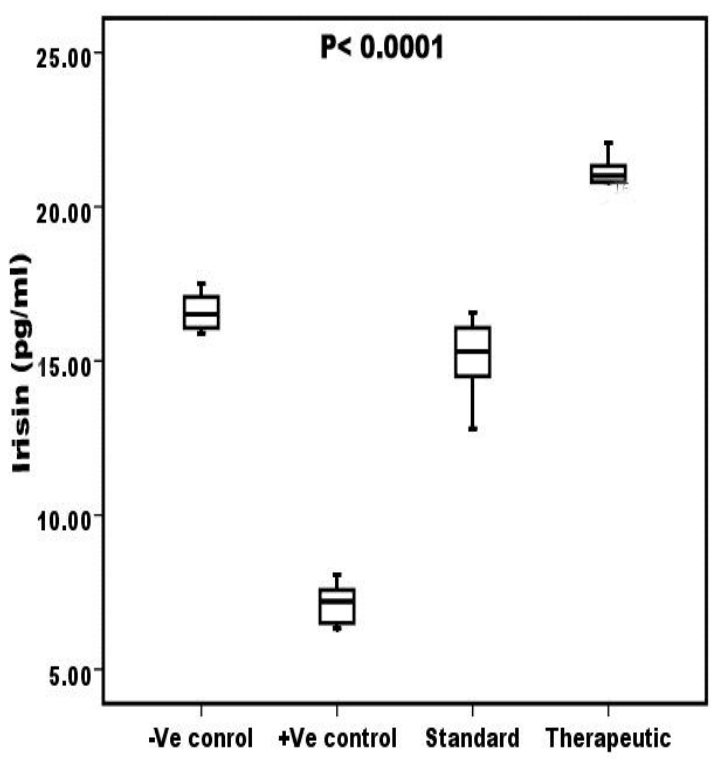

Fig. (8): Box plots of Irisin for comparison between Different studied groups

-ve $=$ Negative control and $+\mathbf{v e}=$ Positive control.

The box represents the interquartile range. The whiskers indicate the highest and lowest values, and the line across the box indicates the median value. Overall significance of differences between laboratory data of all Groups was determined by ANOVA test ( $\mathrm{p}<$ 0.0001). 


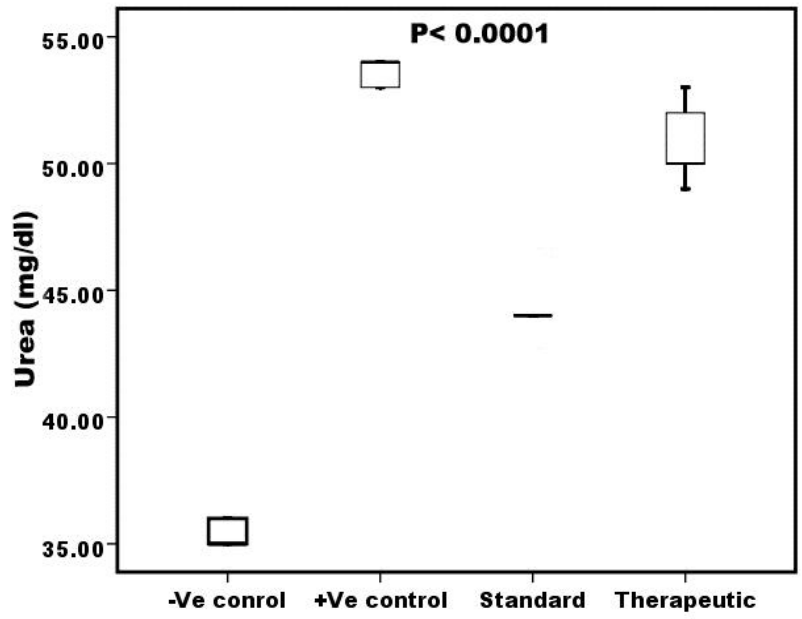

Fig. (9): Box plots of urea for comparison between between studied groups 23).

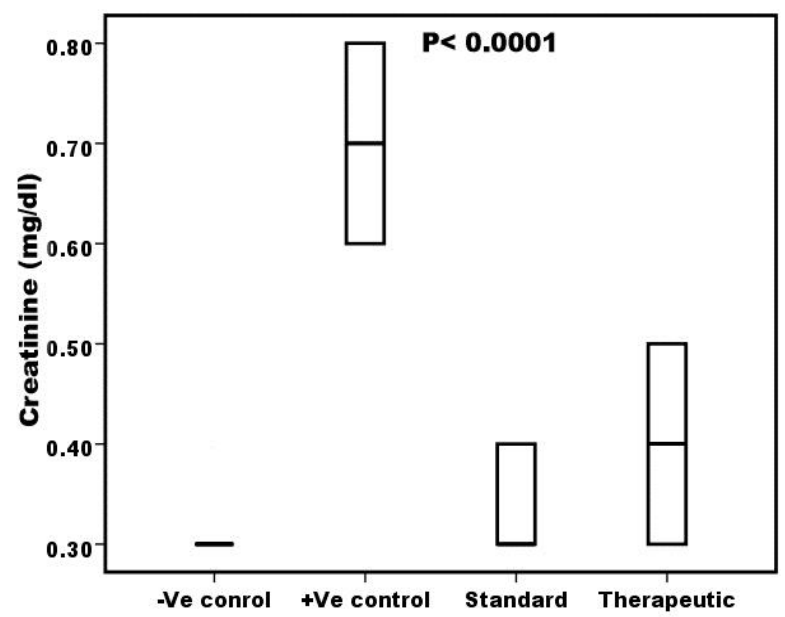

Fig. (10): Box plots of creatinine for comparison studied groups

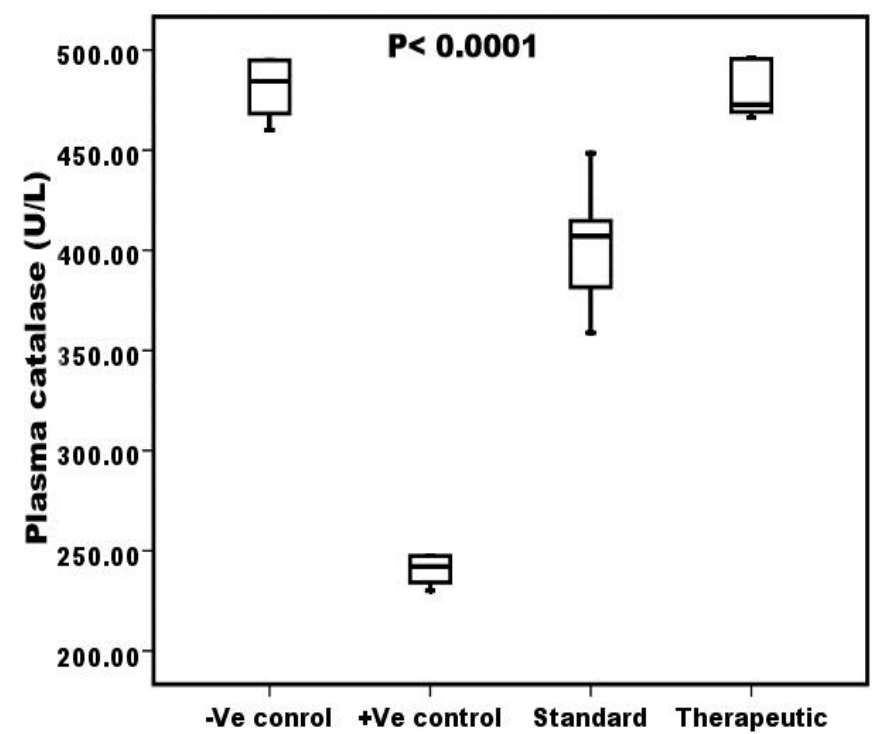

Fig. (11): Box Plots of catalase in plasma from different studied groups

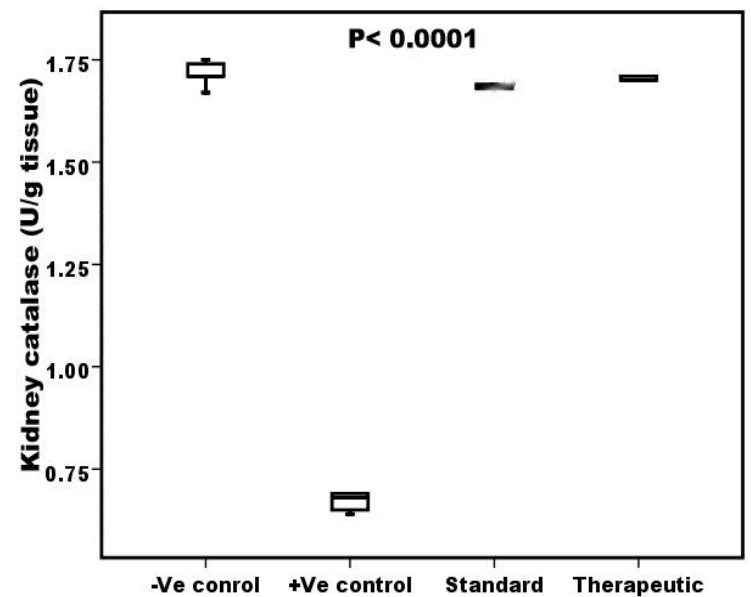

Fig. (13): Box plots of catalase in kidney tissue from different studied groups

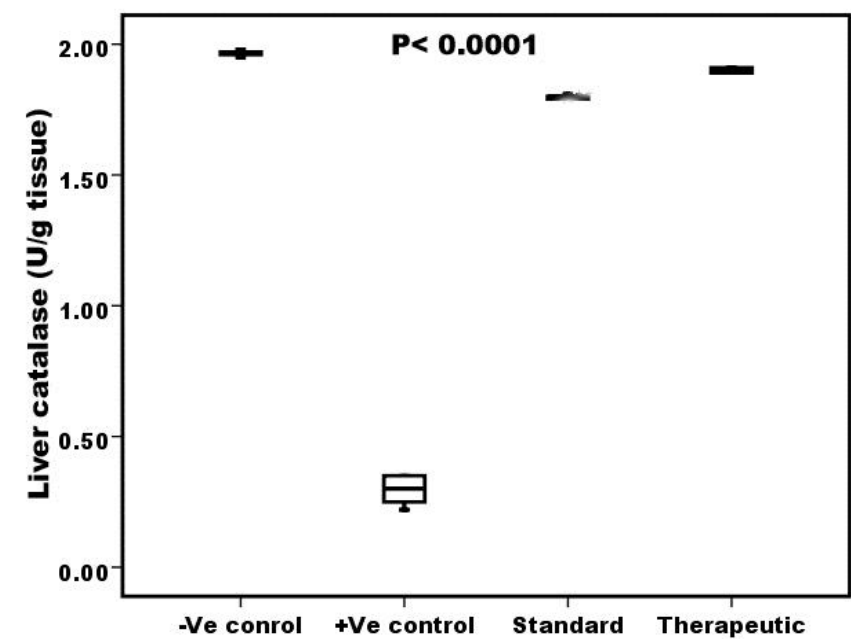

Fig. (12): Box plots of catalase in liver Tissue from different studied groups

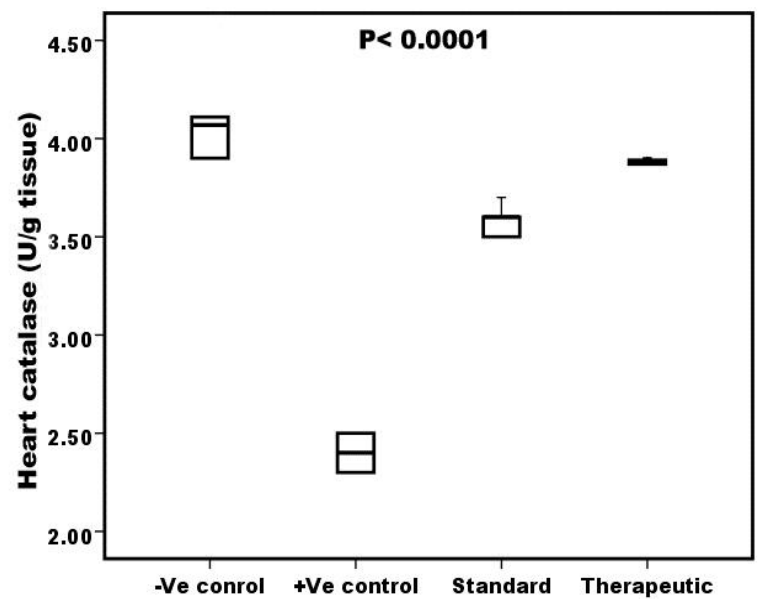

Fig. (14): Box plots of catalase in heart tissue from different studied groups 


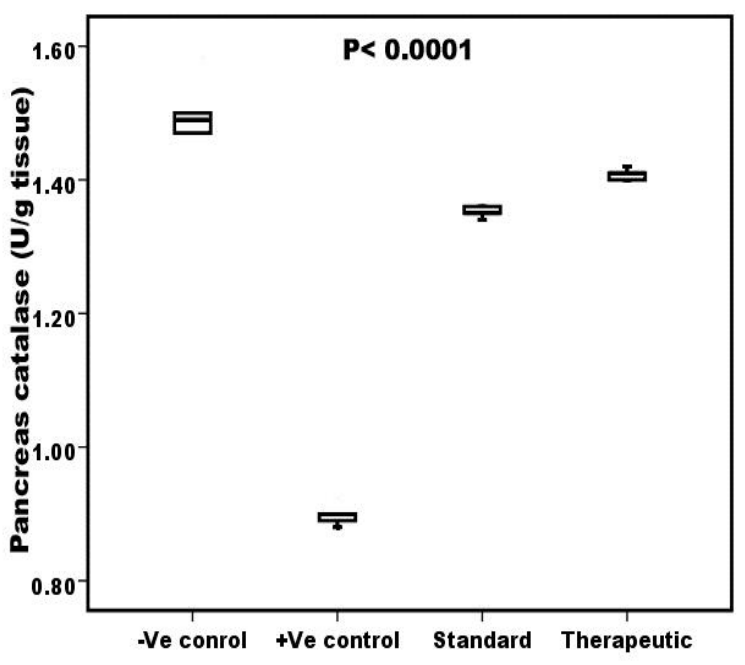

Fig. (15): Box plots of catalase in pancreas tissue from different studied groups

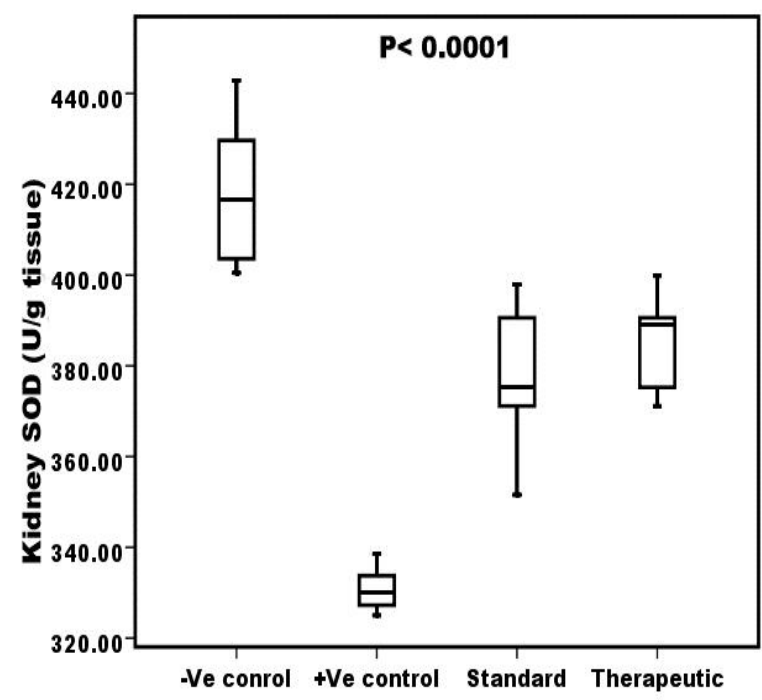

Fig. (17): Box plots of superoxide dismutase in kidney tissue from different studied groups

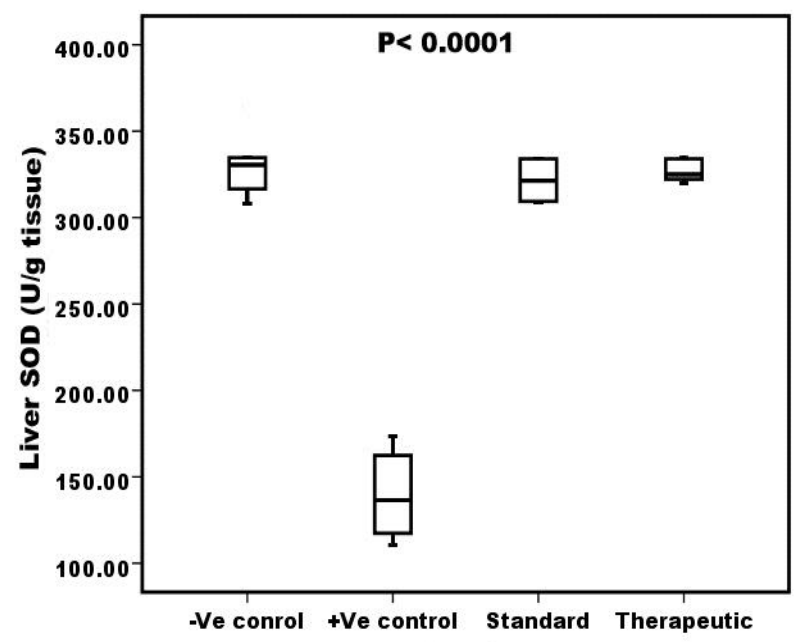

Fig. (16): Box plots of superoxide dismutase in liver tissue from different studied groups

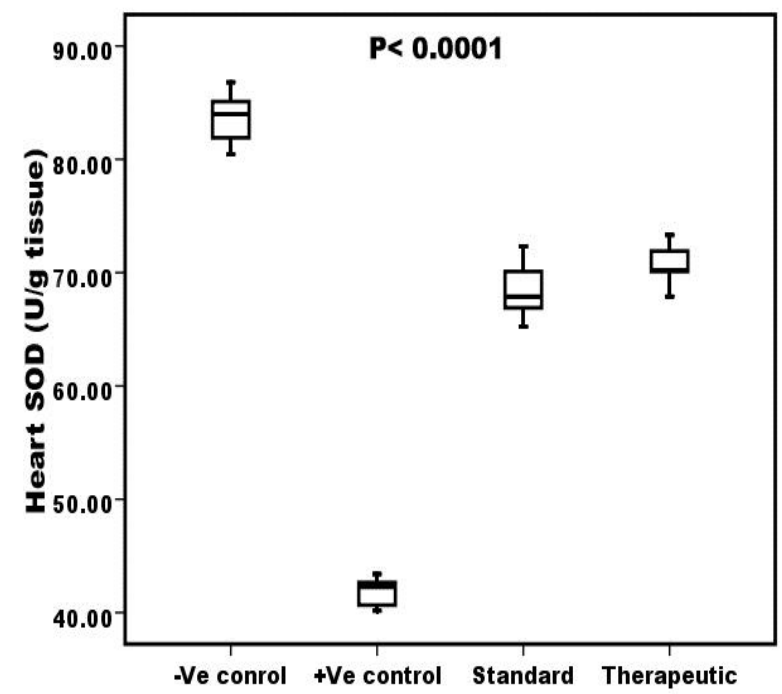

Fig. (18): Box plots of superoxide dismutase in heart tissue from different studied groups 


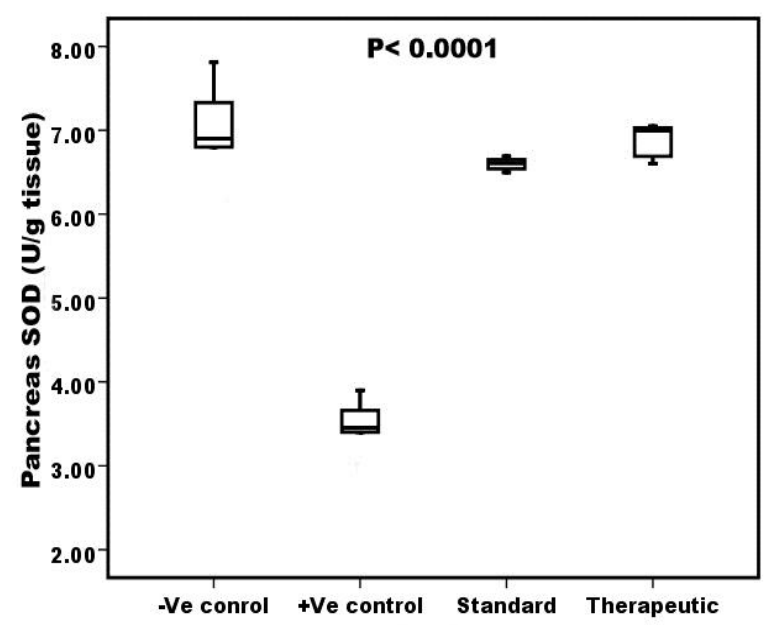

Fig. (19): Box plots of superoxide dismutase in pancreas tissue

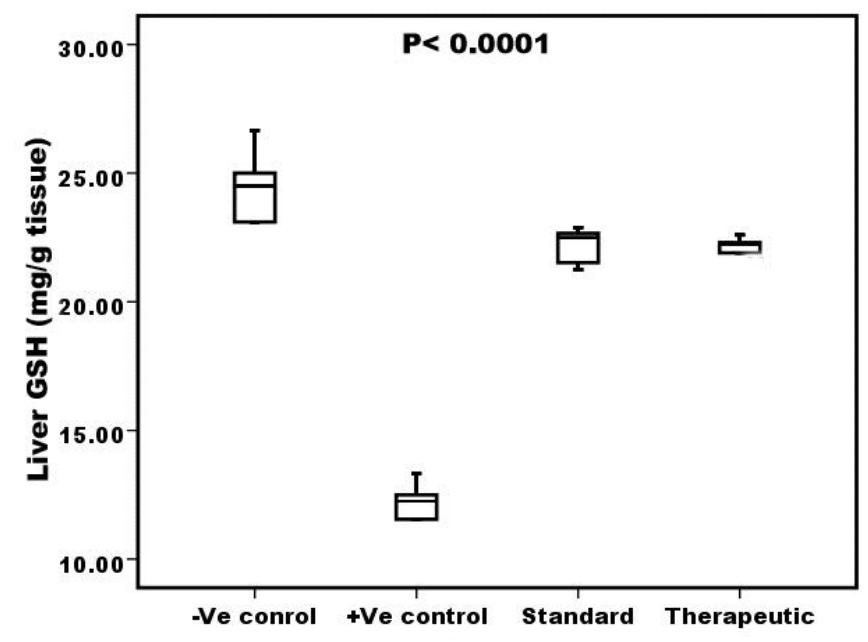

Fig. (20): Box plots of Glutathione reduced in liver tissue

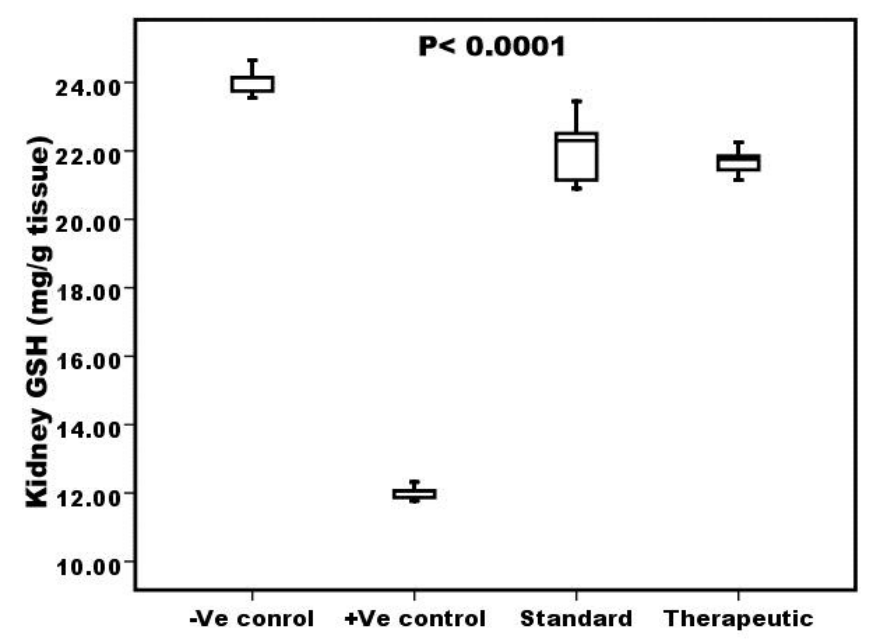

Fig. (21): Box plots of Glutathione reduced in kidney tissue

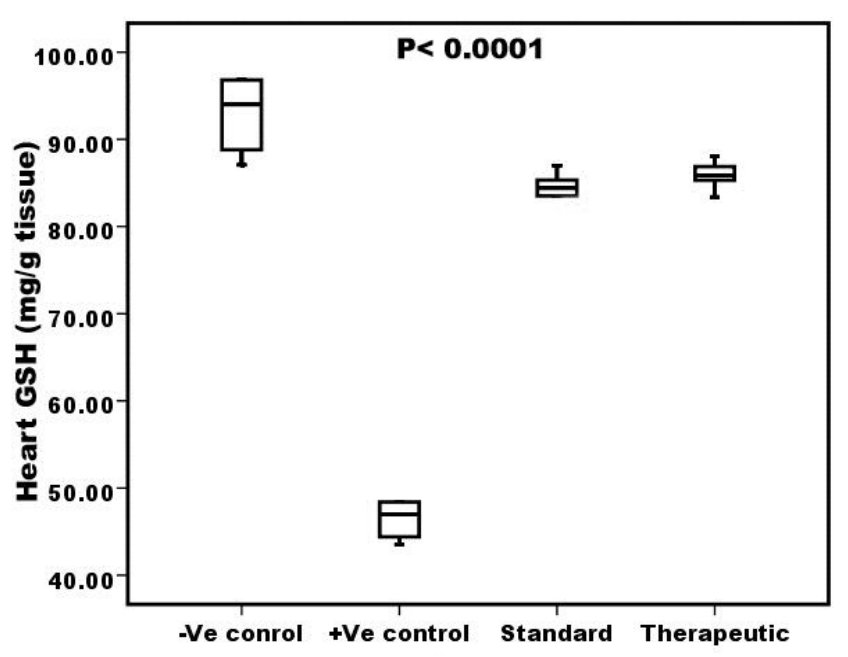

Fig. (22): Box plots of Glutathione reduced in heart tissue

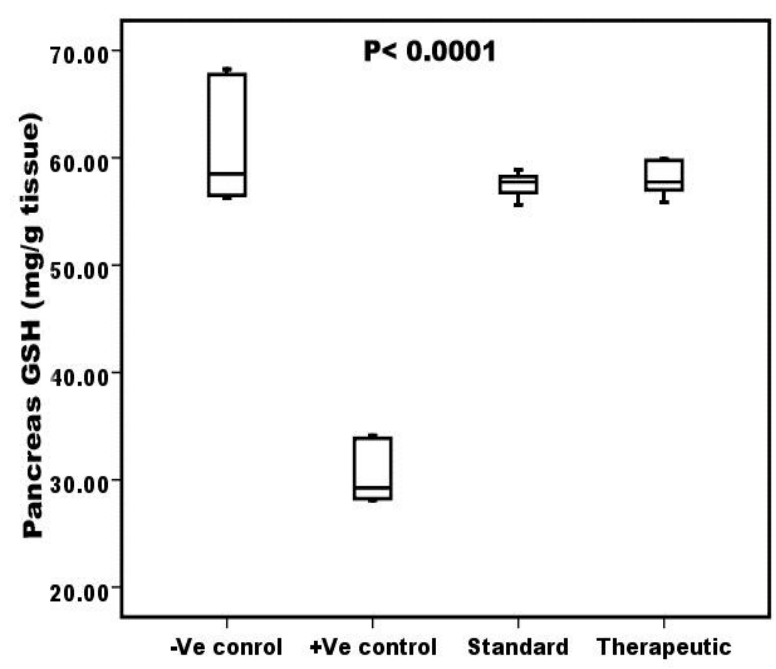

Fig. (23): Box plots of Glutathione reduced in pancreas tissue 


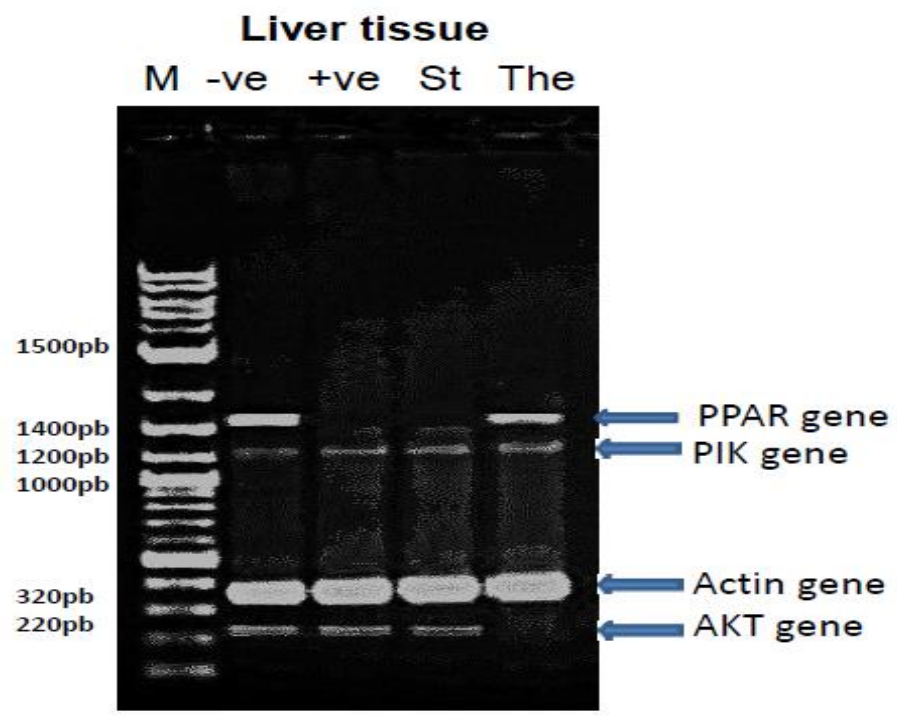

Fig. (24): The effect of Resveratrol on different genes in liver tissue

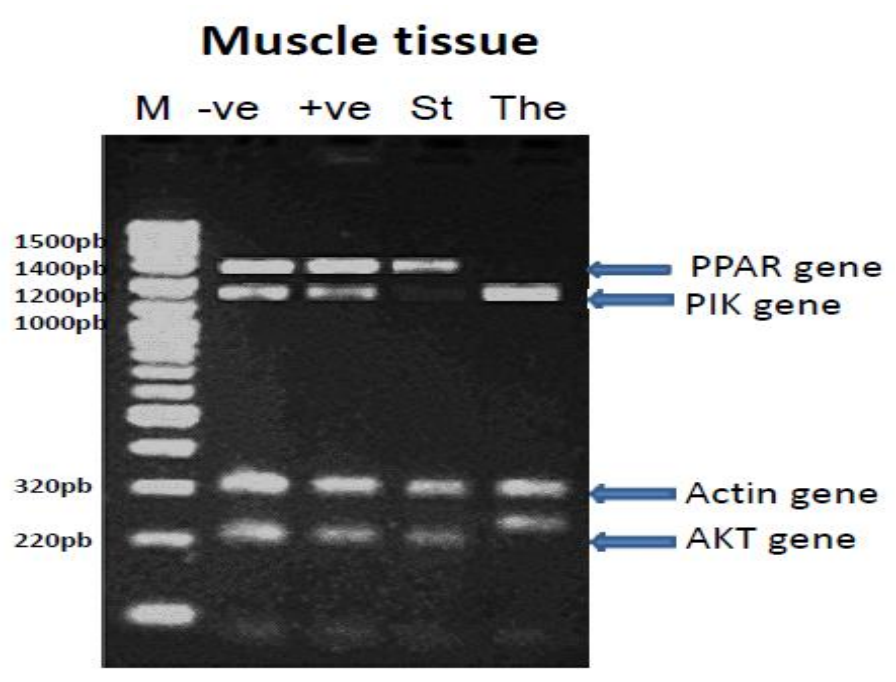

Fig. (25): The effect of resveratrol on different genes in skeletal muscle

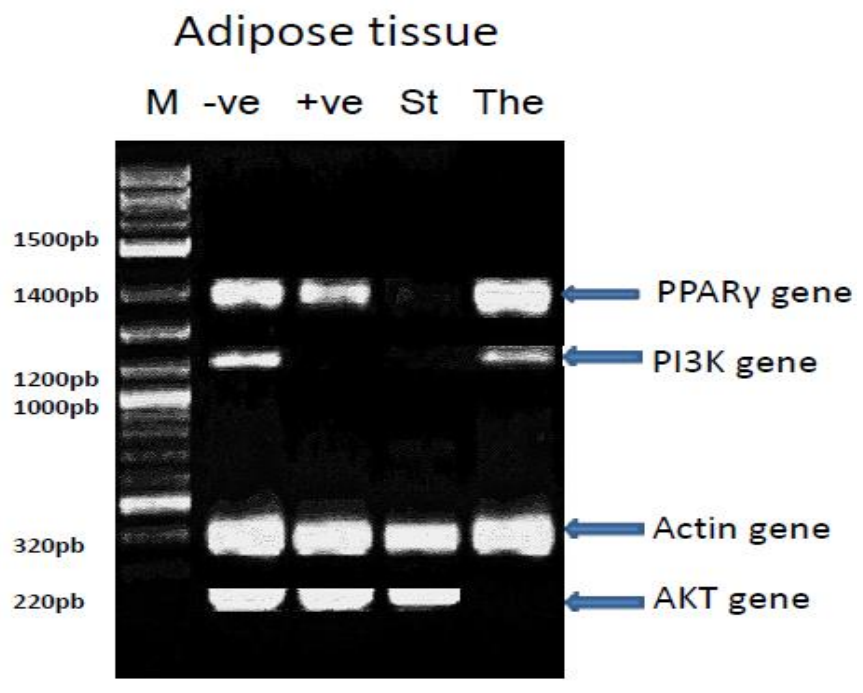

Fig. (26): The effect of Resveratrol on different genes in Adipose tissue

M: DNA Marker, -ve: Negative control, +ve: positive control (diabetic group), St: standard (Metformin) group, The: Therapeutic (Resveratrol) group

\footnotetext{
-ve MGETLGMPPVDSEHGAFASALPMSTSQEITMVSTEMPEWPTNFG

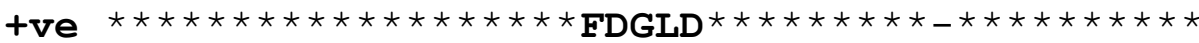

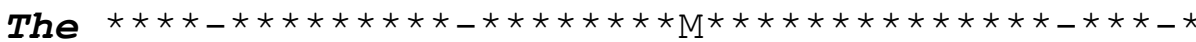

-ve ISSVDLSVMDDHSHSFDIKPFTTVDFSSISAPHYEDIPFTRADPMVA

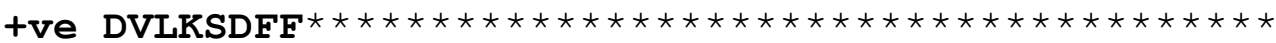

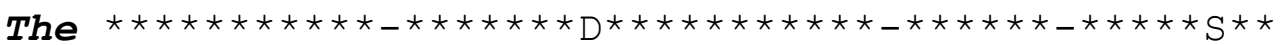




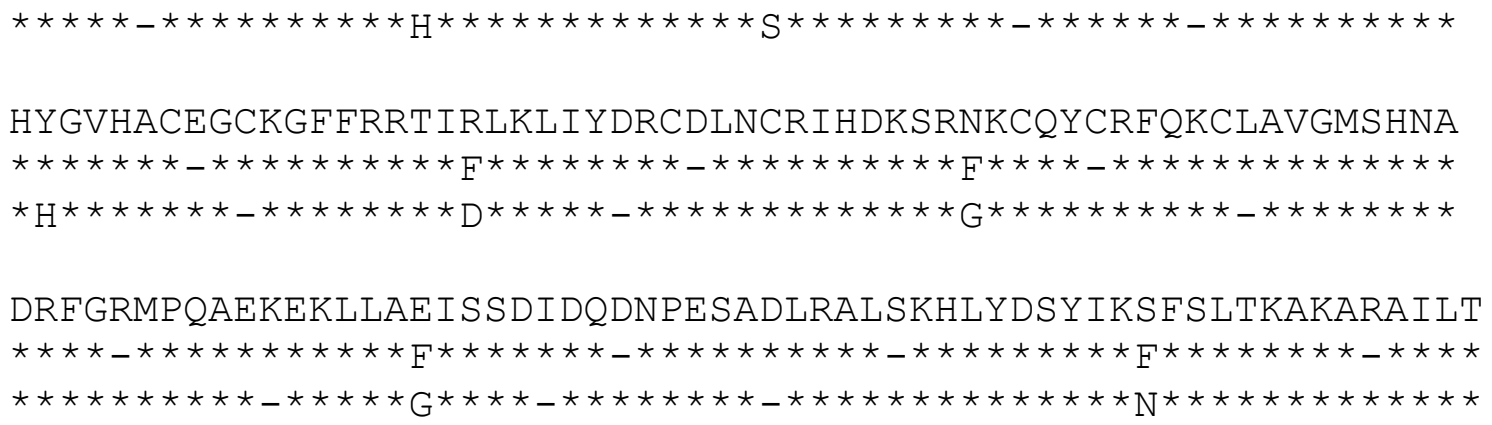

\section{Fig. (27): Amino acid sequence alignment of the (PPAR $\gamma$ ) Adipose tissue}

(-ve): Negative control, (+ve): positive control (diabetic group), and (The): Therapeutic (Resveratrol) group. Mismatching amino acids are shown in bold. Symbols in "consensus" line show the biochemical similarity of mismatching amino acids.*means the same amino acids: - high degree of similarity, and space - completely dissimilar amino acids. 